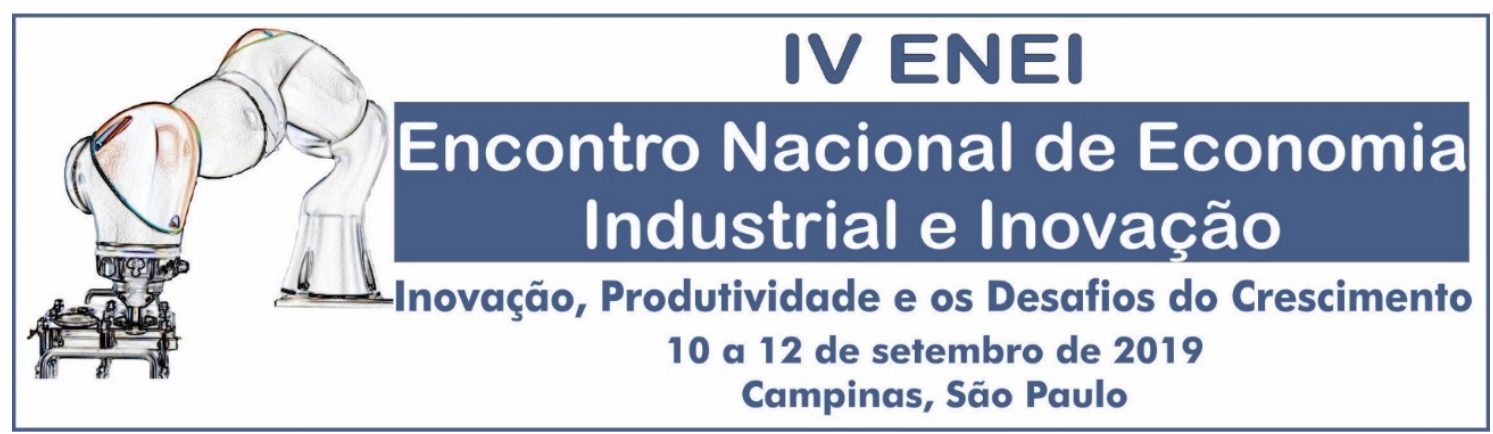

Indústria 4.0 e as redes globais de produção e inovação em serviços intensivos tecnologia: uma tipologia e apontamentos de política industrial e tecnológica

Antônio Carlos Diegues

Núcleo de Economia Industrial e da Tecnologia Professor do Instituto de Economia - UNICAMP diegues@unicamp.br

José Eduardo Roselino

Professor da UFSCar, Campus Sorocaba jeroselino@gmail.com

Resumo: Este artigo apresenta um esforço analítico voltado ao desenho de políticas para a promoção de tecnologias associadas à indústria 4.0. Assim, a partir da proposição de uma tipologia de configuração das redes globais de produção, concebe um marco analítico para embasar a elaboração de uma estratégia nacional voltada à indústria 4.0 centrada no fomento às tecnologias de informação e comunicação. Como resultado, conclui-se que essa estratégia deveria se estruturar em quatro eixos: (a) desenvolvimento tecnológico local (quando há elevada efetividade das políticas e elevado nível de desenvolvimento das competências tecnológicas); (b) fomento a atividades de médio valor agregado, vinculadas à estrutura produtiva doméstica (reduzida efetividade e elevado desenvolvimento); (c) fomento à competitividade sistêmica e financiamento às empresas de base tecnológica (elevada efetividade e reduzido desenvolvimento) e, (d) incorporação de tecnologias e de fomento à sua difusão com vistas a aumentar a produtividade da estrutura produtiva (reduzida efetividade e reduzido desenvolvimento).

Palavras-Chave: Indústria 4.0, Política Industrial e Tecnológica, Redes Produtivas Globais

Abstract: The paper presents an analytical effort focused on the design of national industrial and technological policies aimed to promote technologies associated with the emergence of Industry 4.0. This analysis is based on the understanding of different forms of internationalization of services activities associated to information and communication technologies, since these are considered as the hard core of this new productive paradigm.

Keywords: Industry 4.0, Industrial and Technological Policy, Global Productive Networks JEL: O14; O25; L86. 


\section{Indústria 4.0 e as redes globais de produção e inovação em serviços intensivos tecnologia: uma tipologia e apontamentos de política industrial e tecnológica}

\section{Introdução}

O advento de um paradigma tecno-econômico associado à emergência e difusão de tecnologias associadas ao conceito de indústria 4.0, bem como as novas morfologias de estruturas produtivas e inovativas internacionalizadas reforçam o imperativo de se refletir sobre desenhos de políticas industriais e tecnológicas mais adequados às transformações em curso.

Neste contexto, o artigo pretende contribuir para o debate a partir de uma perspectiva centrada na análise das diversas formas de internacionalização das atividades de serviços intensivos em tecnologia, especificamente dos serviços voltados às tecnologias de informações e comunicação (TIC). Essas tecnologias compõem o núcleo duro das formas avançadas de manufatura nos mais diversos segmentos produtivos.

Parte-se da ideia de que o desenho de políticas industriais e tecnológicas voltadas à indústria 4.0 poderia ter como objeto prioritário o desenvolvimento de suas mais importantes tecnologias habilitadoras, relacionadas primordialmente aos serviços de informação em comunicação.

Para tanto, é importante considerar que as atividades que compõem essas tecnologias não são homogêneas em termos de intensidade tecnológica, determinantes da competitividade e estruturas de mercados. A essas dimensões distintivas desse universo de atividades se soma ainda a existência de diferentes formas de internacionalização voltadas ao desenvolvimento das TICs.

Um aspecto peculiar das tecnologias de informação e comunicação é o de que elas trazem já como marca de nascença o seu caráter global. São atividades que se desenvolveram em conjunto com o avanço da globalização produtiva, provendo ao mesmo tempo a infraestrutura informacional e comunicacional necessária à integração global dos mercados, bem como tendo suas características estruturais e competitivas conformadas por esse mesmo movimento de internacionalização. Em outros termos, os serviços de informação e comunicação são simultaneamente genitores e legatários do processo de globalização.

A pertinência de uma política voltada à indústria 4.0 centrada nos serviços de TIC, para o caso brasileiro, justifica-se ainda pela existência prévia de um setor com já expressiva importância econômica e aspectos virtuosos em termos tecnológicos e inovativos. Com base nesses princípios, o trabalho propõe que o desenho de políticas e a escolha dos instrumentos de fomento voltados a essas tecnologias teriam maiores chances de sucesso se tiverem a capacidade de considerar diferentes as configurações existentes dentre as tecnologias de informação e comunicação.

Para fundamentar tal discussão, o artigo está organizado em quatro seções, além dessa breve introdução. A primeira seção apresenta aspectos gerais sobre a emergência do novo paradigma tecnoprodutivo associado à indústria 4.0, destacando a importância TICs como vetores primordiais dessas novas formas de organização das atividades produtivas. Adicionalmente, apresentam-se alguns aspectos determinantes da dinâmica concorrencial específica a essas atividades.

A segunda seção apresenta os aspectos distintivos da internacionalização das atividades de serviços voltados às tecnologias de informação e comunicação, juntamente com a proposição de uma tipologia de diferentes configurações das redes produtivas globalizadas voltadas a essas atividades.

$\mathrm{Na}$ terceira seção, propõe-se um marco analítico concebido para embasar a elaboração de uma estratégia nacional voltada à indústria 4.0 centrada no fomento às tecnologias de informação e comunicação. Parte-se do princípio de que a efetividade dessas políticas é, em grande medida, determinada pela adequação dos seus instrumentos às características específicas das redes que se procura fomentar. Expõe-se com isso, a sugestão de que quatro dimensões deveriam ser consideradas como condicionantes para a adequação dos instrumentos de política: tecnológica, institucional, nível de desenvolvimento da estrutura empresarial e competitividade sistêmica local.

Finalmente, as notas conclusivas são apresentadas e sintetizadas nas considerações finais. 


\section{Indústria 4.0 e a centralidade das tecnologias de informação e comunicação}

As transformações produtivas que se iniciaram no último quartil do século $\mathrm{XX}$ tiverem como principal vetor o desenvolvimento do complexo eletrônico, o qual revolucionou radicalmente o mundo da produção e do trabalho no fenômeno largamente denominado de terceira revolução industrial e tecnológica, conforme já apontava Coutinho (1992).

A construção desse novo paradigma tecno-produtivo trouxe para o núcleo da dinâmica inovativa o desenvolvimento de atividades relacionadas às tecnologias de informação e comunicação, em especial o software e os serviços de informática. Nos primórdios da revolução microeletrônica, o software e os serviços de informática apareciam como coadjuvantes, como atividades secundárias vinculadas ao desenvolvimento dos equipamentos, passando progressivamente a ocupar papel central nas transformações induzidas pelas TICs.

Assim, desenvolve-se a crescente importância econômica desses componentes intangíveis, decorrente do movimento de interpenetração de componentes programáveis nos demais segmentos do complexo eletrônico, caracterizado por Coutinho (1992, p.70) como:

“(...) a aplicação (ou criação por meio dela) da microeletrônica de uma base tecnológica comum a uma constelação de produtos e serviços (que) agrupou um conjunto de indústrias, setores e segmentos na forma de um 'complexo eletrônico', densamente intra-articulado pela convergência intrínseca da tecnologia de informação."

Ou seja, o processo de transformação que teve início com o advento da terceira revolução industrial impulsionou a crescente importância das atividades e processos de produção baseados em informação e conhecimento.

Ernst (2000), por sua vez, identificou como parte desse processo um deslocamento progressivo do "centro de gravidade" na geração do valor econômico, do hardware em direção ao design de padrões de arquitetura, software e serviços intensivos em conhecimento.

Athereye (2005) por exemplo, sugere que os serviços de informática associados ao desenvolvimento de software desempenham no novo paradigma produtivo um papel análogo ao setor produtor de bens de capital no paradigma anterior, afirmando que a indústria de software é "(...) mais do que uma indústria qualquer - produz um bem intermediário central na nova economia digital” (ATHEREYE, 2005, p.7).

Essa importância crescente dos serviços associados às tecnologias de informática para as demais atividades produtivas e setores é denominada por Zysman et al (2010, p. 2) como uma revolução algorítmica:

\footnotetext{
"Nós chamamos isso de Revolução Algorítmica. Modelos de negócios tradicionais podem se tornar mais produtivos, estendidos com ferramentas de TIC. E modelos de negócios totalmente novos podem ser criados, oferecendo serviços antes impossíveis a qualquer preço. A revolução algorítmica nos serviços está mudando profundamente a forma como as empresas agregam valor.”
}

A percepção dessa centralidade dos serviços voltados ao desenvolvimento e aplicação de tecnologias informação e comunicação exige um redesenho das políticas públicas, que conforme apontam Zysman et al (2010), deve deixar de identificar fronteiras entre atividades manufatureiras e de serviços, uma vez que a produtividade e inovatividade das atividades produtivas dependem progressivamente do desenvolvimento de sistemas baseados nesses serviços tecnológicos.

"Do ponto de vista da política, a questão é como conceber, projetar, desenvolver e construir e implantar esses novos sistemas. Os empregos "bons", funções de alto valor agregado, estão no desenvolvimento e implantação desses novos sistemas” (ZYSMAN et al, 2010, p.28).

É justamente a partir desse enfoque que se desenvolve originalmente o conceito da indústria 4.0, como uma política deliberada que visa, a partir de uma ênfase no emprego de tecnologias de informação e comunicação, promover um salto tecnológico no setor industrial da Alemanha.

Hirsch-Kreinsen (2016, p.5) narra criticamente o surgimento do termo na Alemanha em 2011: 
“Os criadores desse conceito anunciaram uma 'mudança de paradigma' industrial para a Alemanha com base em novas tecnologias digitais que devem ser realizadas sem demora. Esta projeção insiste que o desenvolvimento industrial está atualmente no limiar de nada menos do que uma nova 'quarta revolução industrial' impulsionada pelo desenvolvimento dramático das possibilidades de aplicação das tecnologias de produção digital e inteligente".

\section{Conforme aponta Santos (2019, p.19), há na literatura}

"um certo ceticismo em relação à caracterização das transformações em curso como uma quarta revolução industrial. A contestação se baseia na proposição de que esse processo, definido como Indústria 4.0, significa uma continuação ou desdobramento da terceira revolução industrial."

Nesse sentido, HirschKreinsen (2016) aponta que a Indústria 4.0 estaria identificada com a terceira revolução industrial, uma vez que se baseia na centralidade das tecnologias produtivas intensivas em TI. Jasperneite (2012), por sua vez, sugere que a pretensão de apresentar essas tecnologias como parte de uma quarta revolução industrial se assemelha à expressão em língua inglesa "old wine, new bottle" (mesmo vinho, nova garrafa).

Na mesma linha de identificação da Indústria 4.0 como intensificação de um processo identificado com a terceira revolução industrial, Broedner (2015) refere-se à Indústria 4.0 como uma "revolução de palavras", uma vez que diz respeito à aplicação intensificada de tecnologias digitais aos processos produtivos.

A partir deste debate, o presente trabalho apoia-se na percepção de que as transformações associadas à indústria 4.0 são importantes e representam um fenômeno tecnológico de grande relevância. No entanto, em consonância com os autores mencionados, esse artigo situa-se dentre aqueles que enxergam no fenômeno elementos de continuidade com o processo da terceira revolução industrial, uma vez que o revolucionamento das atividades produtivas por meio da pervasividade das tecnologias de informação e comunicação (referidas por Coutinho, 1992, como "telemática") é um movimento iniciado ainda em fins do século passado.

A despeito dessa contenda semântica ou conceitual, preserva-se como argumento deste artigo que a análise das características próprias à dinâmica concorrencial e às formas de internacionalização dessas atividades são essenciais para a proposição de políticas voltadas ao desenvolvimento da indústria 4.0 no Brasil.

\section{Dinâmica concorrencial e redes globais de produção e inovação em serviços intensivos em tecnologia: uma proposta de tipologia}

A organização das atividades de serviços intensivos em conhecimento (dentre as quais as atividades de tecnologia de informação e comunicação - TIC se destacam) em escala global deve ser compreendida a partir de um contexto mais amplo vigente nas últimas décadas século XX marcado pela acentuação do fenômeno da globalização econômica e pela consolidação das Global Flagship Networks como o novo paradigma de organização empresarial dominante no século XXI.

Surgido inicialmente na indústria eletrônica norte americana, tal modelo de organização empresarial espraiou-se gradativamente para um conjunto amplo de atividades manufatureiras, notadamente aquelas nas quais as diversas etapas dos processos produtivos eram mais susceptíveis de serem organizadas em sistemas modulares. Neste cenário, na medida em que os avanços nas TIC permitiam que os processos de gestão empresariais fossem organizados a partir do princípio da digitalização das informações, e que a liberalização econômica e financeira reduzia significativamente as restrições à movimentação do capital e da produção, a empresa organizada a partir da lógica de rede torna-se o principal agente da transnacionalização do capital (CHESNAIS, 1996).

A grande corporação global, ao se especializar nas atividades responsáveis pela criação de assimetrias competitivas em seus respectivos setores de atuação, e dispersou em escala global outras atividades hierarquicamente inferiores (para, simultaneamente integrá-las), situa-se na base do que Ernst \& Kim (2002) descrevem como Global Flagship Networks. Nestas redes, as estratégias de produção e de 
inovação (em última instância, de valorização do capital) são formuladas em escala global e envolvem a interação sistemática dos diversos elos da rede. Assim a atuação de tais elos se configura como uma parcela de um conjunto muito mais amplo de atividades intrinsecamente relacionadas, as quais são dispersas em escala global de modo a assegurarem o acesso rápido e a baixo custo a recursos, capacitações e conhecimentos complementares às competências core das empresas controladoras das redes (ou capitânias).

Apesar de inicialmente restritas às atividades manufatureiras, a partir da tendência de adoção de processos modularizados de produção e desenvolvimento das atividades de TIC, tais empresas também se tornaram vetores importantes da internacionalização dos serviços intensivos em tecnologia. Assim, em um movimento análogo ao de outros setores, observa-se o surgimento de redes globais nestes serviços, nas quais tanto as atividades de produção como de desenvolvimento passam a serem segmentadas em módulos e são realizadas por agentes especializados e dispersos em escala global.

Como resultado deste fenômeno as empresas controladoras das redes apresentam a tendência de concentrarem suas atividades em etapas hierarquicamente superiores do processo produtivo e de desenvolvimento, como análise de requisitos e de demandas, e design de alto nível.

Em contrapartida, as etapas mais intensivas em atividades rotineiras e mais próximas do que pode ser entendido, grosso modo, como o processo de "fabricação dos serviços de tecnologia de informação e comunicação" como a codificação / programação e teste, e as atividades de manutenção e suporte técnico básico são alvos de processos de outsourcing. Ou seja, em geral as empresas capitânias mantém in house as atividades mais intensivas em conhecimento, com alto potencial inovativo e que são importantes elementos diferenciadores e fontes de assimetrias competitivas, e externalizam para os demais elos constituintes de sua rede de produção as atividades menos nobres.

Um adequado entendimento da dinâmica concorrencial dos serviços intensivos em conhecimento também se faz necessário para o desenvolvimento da análise proposta. A heterogeneidade existente dentre o conjunto de atividades de serviços relacionados às tecnologias de informação e comunicação desdobrase em diferentes dinâmicas concorrenciais (ROSELINO, 2006).

Há, por um lado, uma inegável tendência de concentração dos mercados em alguns segmentos, com a conformação de estruturas de mercado oligopolizadas ou mesmo monopólios estabelecidos de facto. Essa tendência à concentração coexiste, no entanto, com a percepção de significativas oportunidades para o sucesso de novos entrantes, com generosas possibilidades de sucesso para startups e empreendimentos inovadores.

Esse aparente paradoxo se explica, conforme Roselino (2006), pela já referida heterogeneidade que caracteriza essas atividades, resultando em diferentes padrões de concorrência. A existência de fortes barreiras à entrada de novos competidores e tendência ao monopólio, assim como a existência de significativas oportunidades de entrada de novos competidores, coexistem como "tendência" e "contratendência”.

A tendência centrípeta está estritamente vinculada aos efeitos decorrentes das economias de rede. Assim, a partir das constatações de Arthur (1998), destaca-se que estas economias tendem a gerar externalidades positivas crescentes, as quais beneficiam todos os segmentos relacionados a determinado sistema (firmas produtoras, fornecedoras e usuários, entre outros). Com o intuito de buscar se apropriar ao menos de parcelas destes benefícios, cada vez mais novos usuários e novos produtores de soluções (novos módulos) complementares são atraídos para o sistema, o que contribui para sua consolidação. Em virtude deste movimento de consolidação destaca-se uma tendência de concentração dos recursos financeiros nos agentes responsáveis pela concepção e pelo design do sistema, movimento este que em determinadas circunstâncias gera mecanismos de feedback tão fortes que podem até implicar na constituição de estruturas monopolistas.

Já a tendência centrífuga atua no sentido de tornar as estruturas de mercado menos concentradas. O principal incentivo a este movimento de desconcentração de mercado está associado à redução das barreiras à entrada viabilizadas pelo movimento de segmentação das capacitações que caracteriza os processos de modularização das TIC. Assim, o alto dinamismo tecnológico destas, ao permitir a constante criação de 
novas funcionalidades incentiva o surgimento de novos entrantes. Estes novos entrantes, além de se beneficiarem do fato da criação de módulos e funcionalidades complementares não exigir o domínio das capacitações core do sistema, também se beneficiam das externalidades de rede que se associam aos sistemas já consolidados, fato este que reduz significativamente as incertezas na introdução das inovações no mercado.

A interação entre estas tendências centrípeta e centrífuga passa a ser então o vetor responsável pela configuração das estruturas de mercado nas atividades de TIC. A maneira e a intensidade com que cada uma destas forças se apresenta, por sua vez, depende em grande parte da estabilidade dos padrões tecnológicos vigentes e da generalidade das respectivas tecnologias que caracterizam cada segmento deste paradigma. Assim, tendência centrípeta é dominante nos períodos de estabilidade dos padrões tecnológicos e em segmentos nos quais as soluções desenvolvidas apresentam alto grau de generalidade, enquanto que a tendência centrífuga é dominante nos períodos de instabilidade e rupturas nestes padrões e em segmentos nos quais as tecnologias são bastante específicas

A partir desta perspectiva, este artigo busca trazer uma contribuição à interpretação deste fenômeno, que teria lugar no núcleo do novo paradigma técnico-econômico da indústria 4.0, ao propor uma tipologia para a classificação das redes de produção e inovação nas atividades de serviços intensivos em tecnologia, com destaque para as TICs. Tal tipologia, conforme pode ser observado na figura 1, busca classificar estas redes em quatro níveis principais - um deles com três subníveis.

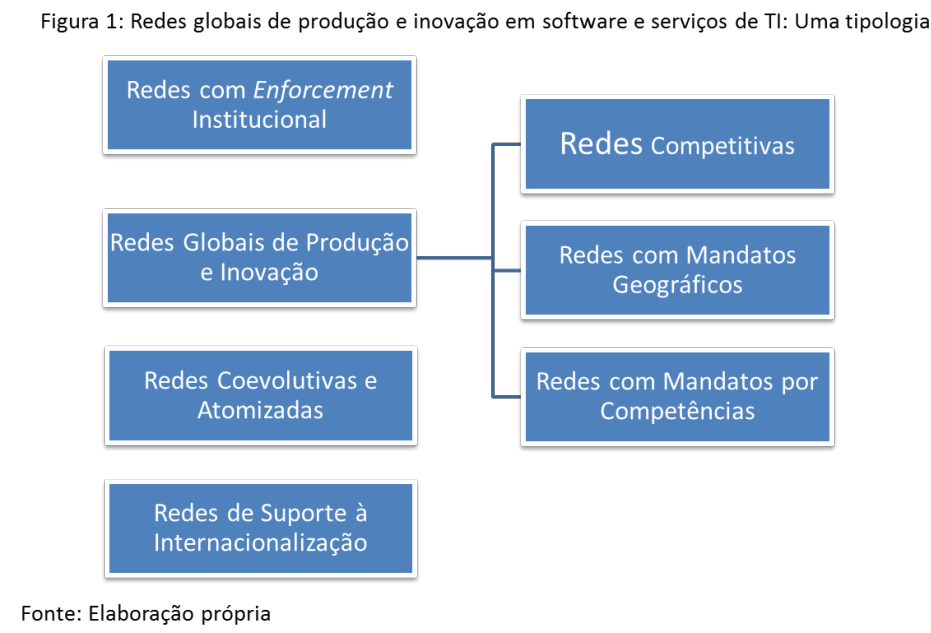

O critério inicial utilizado para a classificação destas redes está relacionado aos principais fatores que levaram à formação da referida rede. Assim, por exemplo, as redes com Enforcement Institucional, como o próprio nome sugere, normalmente foram construídas a partir de exigências de determinadas legislações locais como a obrigatoriedade de conteúdo nacional, condicionalidade no acesso aos mercados e a políticas de incentivos locais, entre outros fatores.

Este forte componente geográfico, por sua vez, é pouco significativo para as redes aqui denominadas como Coevolutivas e Atomizadas. Isso porque estas se organizaram de maneira mais difusa, em torno de um amplo ecossistema de fornecedores associados a determinada plataforma tecnológica, como no caso dos ofertantes de apps para os sistemas operacionais Android e iOS.

A fim de traçar uma análise comparativa entre cada um dos diferentes tipos de redes propostos, buscar-se-á responder para cada uma delas, as seguintes perguntas:

a) Quais são as estruturas típicas destas redes?

b) Quais são as principais fontes de assimetrias competitivas que devem ser buscadas pelas empresas que constituem estas redes?

c) Quais são os determinantes da competitividade sistêmica de todos os agentes destas redes?

d) Quais são as principais atividades realizadas pelas empresas constituintes das redes?

e) Como são determinadas as estratégias de distribuição do valor gerado pela rede entre as diversas empresas constituintes destas? 
O primeiro bloco da tipologia de redes proposta por este artigo refere-se às Redes com Enforcement Institucional (figura 2). Estas são formadas não exclusivamente a partir de decisões estratégicas das empresas capitânias, mas principalmente devido a exigências institucionais de caráter nacional, dentre as quais se destacam exigências associadas à obrigatoriedade de grau mínimo de nacionalização da produção, condicionalidade no acesso aos mercados e à políticas de incentivos locais, entre outros fatores. Um exemplo interessante neste sentido é o desenvolvimento de todo um ecossistema de produção (ainda que frágil) e P\&D associado às exigências da Lei de Informática no Brasil (ROSELINO e GARCIA, 2002; SALLES et al, 2012; COLOMBO, 2009; PROCHNIK et al, 2015).

Como as estruturas das redes variam consideravelmente de acordo com as exigências institucionais, e normalmente as principais atividades realizadas nestas redes referem-se à $\mathrm{P} \& \mathrm{D}$ local e ao desenvolvimento de conteúdo nacional (as quais são executadas por filiais ou até mesmo subunidades / divisões das empresas multinacionais localmente estabelecidas), o principal determinante da competitividade sistêmica da rede reside nos benefícios, em geral tributários, ofertados como contrapartidas das exigências institucionais locais. Apesar deste ser o maior elemento responsável pela existência e pela competitividade das redes, com o intuito de potencializar sua estratégia de acumulação de capital, as empresas capitânias atuam no sentido de fomentar competitividade dos elos locais por meio da capacidade de internalizar competências e gerar inovações a partir das exigências institucionais.

Neste cenário, a geração do valor na rede é bastante difusa, pois os resultados podem ser incorporados pela unidade local (quando esforços se derivam do desenvolvimento de conteúdo nacional) ou majoritariamente pela empresa capitânia quando os resultados das exigências institucionais transformam-se em produtos ou serviços incorporados no portfolio global de módulos da rede (quando os esforços são em P\&D). Neste segundo caso, assim como ocorre nas Redes com Mandatos por Competências (figura 6), há dificuldade de mensuração da contribuição de um módulo específico para o valor do produto final e a unidade executora do mesmo é remunerada segundo os custos para o desenvolvimento do referido módulo.

Figura 2: Redes com Enforcement Institucional

\begin{tabular}{|c|c|}
\hline & Redes com Enforcement Institucional \\
\hline $\begin{array}{l}\text { Determinantes da } \\
\text { Competitividade } \\
\text { Empresariais }\end{array}$ & $\begin{array}{c}\text { Capacidade de internalizar competências e gerar inovações a partir das } \\
\text { exigências institucionais (sejam elas de esforços inovativos ou de } \\
\text { desenvolvimento de conteúdo nacional) }\end{array}$ \\
\hline $\begin{array}{l}\text { Determinantes da } \\
\text { Competitividade } \\
\text { Sistêmicos }\end{array}$ & $\begin{array}{l}\text { Benefícios, principalmente tributários, como contrapartidas das exigências } \\
\text { institucionais locais }\end{array}$ \\
\hline Estrutura da Rede & $\begin{array}{c}\text { Varia consideravelmente de acordo com as exigências institucionais. Em geral } \\
\text { são sub-unidades/ divisões das empresas multinacionais localmente } \\
\text { estabelecidas }\end{array}$ \\
\hline $\begin{array}{l}\text { Tipos de Atividades } \\
\text { Realizadas }\end{array}$ & Basicamente atividades de P\&D local e desenvolvimento de conteúdo nacional \\
\hline Valoração & $\begin{array}{c}\text { Valoração difusa, pois resultados ou são incorporados pela unidade local } \\
\text { (quando esforços se referem ao desenvolvimento de conteúdo nacional) ou são } \\
\text { incorporados no portfolio global de módulos da rede (quando os esforços são } \\
\text { em P\&D). Neste segundo caso, há dificuldade de mensuração da contribuição de } \\
\text { um módulo específico para o valor do produto final }\end{array}$ \\
\hline
\end{tabular}

Fonte: elaboração própria

O segundo bloco de Redes aqui propostas é o de oevolutivas e Atomizadas (figura 3). Estas não são estabelecidas a partir de critérios geográficos e, ao contrário das redes analisadas a seguir, possuem uma distribuição geográfica não definida a priori. Assim, apresentam uma estrutura em permanente evolução, seja no que diz respeito aos agentes integrantes ou à localização geográfica destes. Ou seja, o elemento fundamental para determinar a organização destas redes não é o componente geográfíco, e sim a associação a uma plataforma tecnológica ${ }^{1}$ dominante e seu respectivo ecossistema de fornecedores de módulos e produtos complementares.

\footnotetext{
${ }^{1}$ A partir de uma abordagem ampla, semelhante àquela adotada por autores como BRESNAHAN \& GREESTEIN (1999), GAWER \& HENDERSON (2005), CUSUMANO \& GAWER (2001) e WEST (2003) a plataforma tecnológica pode ser
} 
De maneira geral, sua estrutura é formada por um número bastante reduzido de empresas líderes da plataforma, de porte global, e por uma estrutura extremamente atomizada entre os produtores de módulos complementares. É no seguinte sentido que se entende o termo coevolutivo aqui proposto: na medida em que as atividades realizadas pelas inúmeras empresas constituintes da rede dependem da evolução da plataforma, quando esta evolui tais empresas devem necessariamente atualizar seus produtos e serviços de maneira a fazer com que estes continuem compatíveis com a plataforma. Tal fato ocorre, por exemplo, quando empresas constituintes da rede também lançam novas versões de seus apps a fim de adaptá-los a uma nova versão do iOS lançado pela Apple. Em síntese, nota-se que o surgimento desta tipologia de redes é resultado das transformações na forma de organização do desenvolvimento tecnológico e nas estratégias de posicionamento de mercado adotadas por parte das empresas de serviços de TIC, as quais centralizaram sua atuação cada vez mais na busca pela inserção em um espaço privilegiado nas plataformas tecnológicas dominantes.

Neste cenário, a competitividade sistêmica destas redes também está intimamente associada ao desempenho da plataforma tecnológica, uma vez que depende da capacidade desta em criar externalidades de rede. Isso porque tais externalidades criam benefícios que podem ser usufruídos de maneira simultânea e não excludente por todos os agentes constituintes da plataforma. Cusumano \& Gawer (2001, p. 5) justificam este fenômeno ao observar que

“(...) quanto mais pessoas usam produtos organizados em torno de plataformas, existem mais incentivos para que sejam introduzidos produtos complementares, os quais estimulam mais pessoas a comprar ou utilizar os primeiros, estimulando assim mais inovação, ad infinitum" (tradução própria)

Esse ciclo virtuoso causa importantes impactos sobre a valorização da plataforma e da rede, pois a percepção do valor associado à determinada solução tecnológica pelo consumidor varia de maneira diretamente proporcional à capacidade desta solução apresentar um conjunto completo, integrado e padronizado de funcionalidades. Em outras palavras, o valor gerado pela plataforma e pela rede aumenta de maneira mais que proporcional à quantidade de produtos e funcionalidades complementares e integradas entre si que ela oferece. Isso ocorre devido ao fato de que a utilização por parte dos consumidores de soluções que não são compatíveis entre si (ou seja, não pertencem a mesma plataforma) ser muito dispendiosa seja em termos financeiros (devido à necessidade de se adquirir sistemas distintos), em termos de dificuldades de aprendizado na utilização do sistema ou da inexistência de uma massa crítica mínima de usuários que permita a interação.

Já no que diz respeito à competitividade dos agentes, o principal driver consiste na busca por elevado dinamismo tecnológico e time to market, com o intuito de se criar externalidades de rede $e$ lock-in. Ao analisar este fenômeno, Arthur (1990) procura destacar a maneira através da qual as externalidades de rede implicam sólidas assimetrias competitivas para os first movers. É neste ponto que reside a importância para as inúmeras empresas integrantes da rede de desenvolverem produtos ou serviços (mesmo que estes não se configurem como os tecnologicamente mais avançados disponíveis no mercado) capazes de gerar externalidades de rede primeiro que os concorrentes. Cabe destacar, no entanto, que conforme lembra Rosenberg (1976), a definição do timing correto é um fenômeno bastante complexo que depende das expectativas acerca da evolução tecnológica futura. Deste modo, em alguns momentos assim como uma entrada tardia no mercado, uma entrada prematura pode implicar na dificuldade da consolidação dos produtos ou serviços em questão.

Como consequência deste cenário, observa-se que quanto maior é a intensidade das externalidades de rede, maiores são os efeitos de lock-in. Ou seja, devido aos elevados custos de saída os agentes tornamse cada vez mais fiéis a um determinado padrão tecnológico. Nas palavras de Arthur (1990, página 93) "padrões ou convenções tecnológicas, assim como tecnologias específicas, tendem a serem locked-in

entendida como um sistema passível de evolução, constituído por componentes independentes que possuem capacidade inovativa própria. Ao aplicar esta abordagem às atividades de serviços de TIC, uma definição mais específica é aquela que entende uma plataforma como o estabelecimento e a evolução de um conjunto de regras e padrões de arquitetura e interface que possibilitam o processamento independente de tarefas e funcionalidades por meio de módulos distintos. Uma vez que os serviços intensivos em tecnologia apresentam um alto dinamismo inovativo, e que estas transformações tecnológicas exigem cada vez mais o domínio de capacitações bastante específicas, observa-se que grande parte dos módulos constituintes de uma plataforma busca oferecer soluções bastante específicas e complementares a suas funcionalidades core. 
devido à existência de retornos crescentes". A partir deste arcabouço, os agentes procuraram concentrar suas atividades no desenvolvimento de módulos e produtos complementares, a partir de uma plataforma pré-estabelecida.

No que diz respeito à apropriação de valor nas Redes Coevolutivas e Atomizadas, dada a importância da apropriação privada de parcela dos benefícios derivados das externalidades de rede associadas a uma plataforma, compreende-se o grau das assimetrias competitivas possuídas pelas empresas líderes das redes.

Com efeito, Gawer \& Cusumano (2002) destacam que o agente líder é aquele que apresenta maior capacidade de comandar a inovação e a evolução dos padrões tecnológicos vigentes em determinada plataforma. Esse comando é exercido em grande parte através da elaboração de regras e padrões de design que estabelecem e condicionam a evolução das arquiteturas e as interfaces da plataforma. Em suma, os agentes líderes detêm grande capacidade de influenciar as trajetórias tecnológicas das atividades organizadas em torno da plataforma e de sua respectiva rede.

Devido a esta influência, o líder da plataforma (e da rede) ocupa uma posição na cadeia de valor hierarquicamente superior aos demais agente. Como é o responsável pela evolução da plataforma, possui a vantagem de poder definir a segmentação de tarefas e capacitações de modo a construir assimetrias competitivas frente aos demais players. Estas assimetrias, por sua vez, materializam-se em barreiras que limitam a migração dos produtores de módulos complementares para as funções core da rede. Assim, parcela substancial do valor se concentra nas empresas líderes de plataforma. Já o enorme contingente de demais empresas concentra suas atividades na produção de módulos complementares operam em nichos, muitas vezes utilizando a estratégia da cauda longa na qual buscam expandir exponencialmente os usuários de seus produtos ao cobrarem preços unitários bastante reduzidos e, assim, criar externalidades de rede (ANDERSON, 2006).

Figura 3: Redes Coevolutivas e Atomizadas

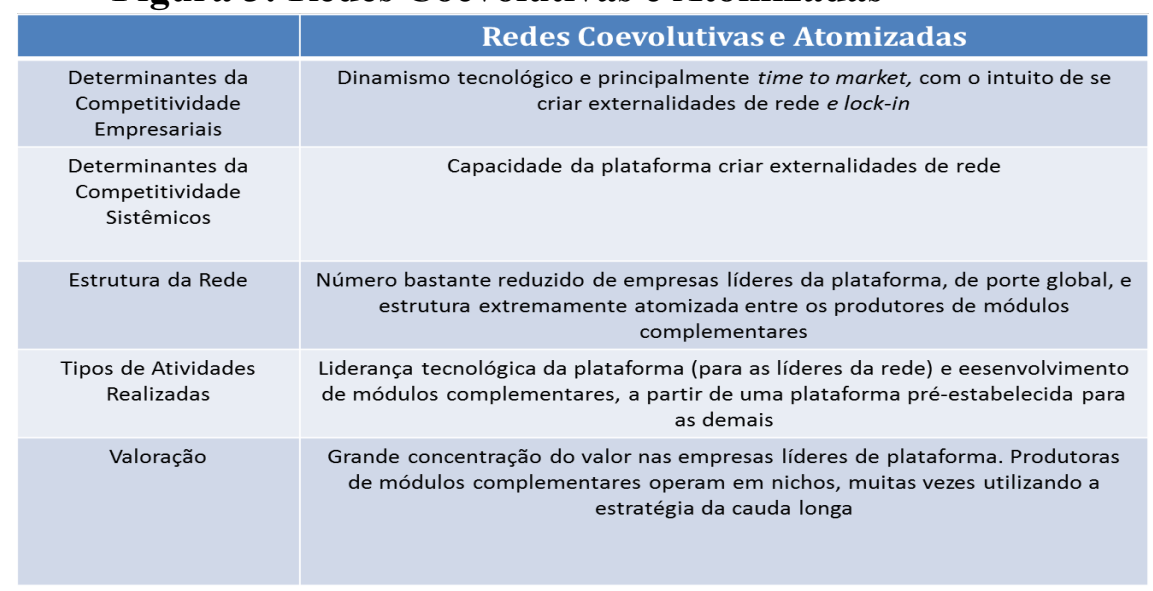

Fonte: elaboração própria

O último bloco da tipologia aqui proposta é constituído pelas Redes Globais de Valorização. De maneira geral, tal bloco é o que mais se aproxima das características das estruturas voltadas às atividades manufatureiras. Tais redes são constituídas principalmente por empresas multinacionais e suas filiais, e organizam-se tanto em torno de atividades de produção quanto de inovação. Em geral é onde se observa com maior ênfase as características do binômio 'maximização do valor acionário \& empresa em rede'.

As empresas comandantes destas redes, conforme foi analisado anteriormente, substituíram a lógica da empresa Chandleriana de reter os lucros e reinvesti-los com o intuito de buscar a diversificação da produção e a verticalização, e passaram a se organizar a partir da lógica de concentração nas atividades core, terceirização das atividades de suporte e com menor capacidade de agregação de valor. Ou seja, na medida em que as empresas líderes das redes se concentram nas atividades com maior capacidade de geração de valor e decidem quais atividades serão terceirizadas e em quais sites globais estarão localizadas, criam redes com um elevado grau de hierarquia tanto no que diz respeito ao tipo de atividade a ser realizada 
por cada uma das empresas componentes desta rede quanto à capacidade destas empresas se apropriarem do valor que será gerado na rede.

Em síntese, tais redes organizam suas atividades por meio de uma estrutura de produção e inovação modular distribuída globalmente. As diferentes maneiras por meio das quais se estruturam esta distribuição permitem qualificar as redes deste bloco em três segmentos distintos: Redes Competitivas, Redes com Mandatos Geográficos ou Redes com Mandatos por Competências.

Nas Redes Competitivas (figura 4) observa-se a constituição de uma estrutura na qual há um grau relativamente baixo de diferenciação entre os seus diversos elos. Ou seja, as inúmeras empresas principalmente as filiais das empresas globais comandantes destas redes - possuem um domínio de um conjunto relativamente amplo de atividades, principalmente as de caráter mais generalista. Em paralelo, também há um conjunto de empresas com parcerias globais e de longo prazo com tais comandantes. Estas parceiras, na maioria dos casos são especializadas em determinadas módulos / atividades específicas da rede.

Neste cenário em que há uma relativa similaridade entre as atividades exercidas pelas filiais e em que há parceiras globais para atividades específicas, o principal fator de assimetria competitiva para as empresas desta rede - sejam elas filiais ou parceiras - é o custo da unidade executora. Ou seja, o que determina a localização das atividades e os movimentos de constante reavaliação desta localização é a competição entre os agentes fundamentalmente via preços - dado que não há grande diferenciação entre a maioria dos elos da rede, as inúmeras empresas têm capacidade de emular uma parte das atividades realizadas pela empresa coordenadora ou capitânia.

Como resultado, com o intuito de manter a competitividade da rede, de uma maneira transversal ou sistêmica, as empresas capitânias buscam alocar as atividades de modo a minimizar a capacidade ociosa na rede global, adequar os prazos e o grau de exequibilidade das funções por parte dos agentes às flutuações da demanda, e reduzir os custos globais da rede. Exemplos ilustrativos destas redes competitivas são aquelas nas quais as grandes multinacionais de serviços intensivos em tecnologia terceirizaram as atividades de fabricação (codificação e testes) para empresas indianas. Outros exemplos são aqueles em que as próprias filiais das empresas capitânias concorrem entre si para a realização de determinado projeto demandando pela matriz. Nesta lógica, a distribuição do valor gerado pela rede entre os agentes se expressa na remuneração por projetos que competem entre si, o que tende a maximizar a capacidade de concentração do valor gerado nas empresas líderes da rede.

Figura 4: Redes Competitivas

\begin{tabular}{|c|c|}
\hline & Redes Competitivas \\
\hline $\begin{array}{l}\text { Determinantes da } \\
\text { Competitividade Empresariais }\end{array}$ & Custos da unidade executora \\
\hline $\begin{array}{l}\text { Determinantes da } \\
\text { Competitividade Sistêmicos }\end{array}$ & $\begin{array}{l}\text { Minimização da capacidade ociosa na rede global } \\
\text { Exequibilidade \& prazo } \\
\text { Custos globais da rede }\end{array}$ \\
\hline Estrutura da Rede & $\begin{array}{l}\text { Filiais das empresas capitânias, em geral com grau de diferenciação entre } \\
\text { elos relativamente baixo e com domínio de conteúdo amplo de atividades } \\
\text { (principalmente as mais generalistas) } \\
\text { Também há um conjunto de parceiras globais especializadas em atividades } \\
\text { específicas }\end{array}$ \\
\hline Tipos de Atividades Realizadas & $\begin{array}{l}\text { Não há grande diferenciação entre os elos. Em geral diversos agentes têm } \\
\text { capacidade de emular uma parte das atividades realizadas pela capitânia }\end{array}$ \\
\hline Valoração & Definida internamente à rede, expressa na remuneração por projetos \\
\hline
\end{tabular}

Fonte: elaboração própria

Outro segmento das Redes Globais de Valoração é aquele denominado como Redes com Mandatos Geográficos (figura 5). A estrutura destas redes, em geral, é constituída por filiais das empresas capitânias distribuídas globalmente, com porte e leque de atividades determinado pela profundidade do mercado em atuação. Assim, variáveis como tamanho e dinamismo dos mercados, grau de sofisticação da demanda e presença de concorrentes globais determinam o conjunto de atividades passíveis de serem realizadas em 
determinado site. Em outras palavras, a partir de um core de atividades comum aos diversos elos da rede há a diferenciação para atendimento dos mercados específicos.

Um caso bastante ilustrativo destas redes é o modelo de desenvolvimento utilizado pela indústria irlandesa de serviços de tecnologia de informação, o qual tem como principal vetor de sua expansão a atuação de filiais de empresas multinacionais com o mandato geográfico de atender o mercado europeu. Deste modo, ao contrário das Redes Competitivas, nas quais os agentes disputavam determinados projetos com base em seus respectivos custos, nestas redes, as empresas possuem mandatos para o atendimento de mercados geográficos específicos. Ou seja, a competitividade da empresa perante a rede na busca por novos projetos e atividades está estritamente vinculada à sua posição geográfica e às características de seu mercado.

Neste cenário, ao buscar impulsionar a competitividade sistêmica da rede, além dos fatores já citados nas Redes Competitivas como exequibilidade, prazo e custos globais, as empresas capitânias buscam minimizar a capacidade ociosa desta. Para tal, em cenários de instabilidade da demanda, deslocam atividades de empresas localizadas em regiões que operam próximas à plena capacidade para aquelas em que se observa elevada capacidade ociosa. Como resultado destes movimentos e das diferentes profundidades dos mercados regionais, a geração de valor depende do dinamismo destes referidos mercados e é subordinada às estratégias de minimização da capacidade ociosa da rede, a qual é definida pela empresa capitânia.

Figura 5: Redes com Mandatos Geográficos

\begin{tabular}{|c|c|}
\hline & Redes com Mandatos Geográficos \\
\hline $\begin{array}{l}\text { Determinantes da } \\
\text { Competitividade Empresariais }\end{array}$ & Alocação geográfica do mercado alvo \\
\hline $\begin{array}{c}\text { Determinantes da } \\
\text { Competitividade Sistêmicos }\end{array}$ & $\begin{array}{l}\text { Minimização da capacidade ociosa na rede global } \\
\text { Exequibilidade \& prazo } \\
\text { Custos globais da rede }\end{array}$ \\
\hline Estrutura da Rede & $\begin{array}{l}\text { Em geral filiais das empresas capitânias, com porte e leque de atividades } \\
\text { determinado pela profundidade do mercado em atuação (volume e } \\
\text { sofisticação da demanda, presença de redes globais concorrentes, etc) }\end{array}$ \\
\hline Tipos de Atividades Realizadas & $\begin{array}{l}\text { A partir de um 'coréde atividades comum aos diversos elos da rede há a } \\
\text { diferenciação para atendimento dos mercados específicos }\end{array}$ \\
\hline Valoração & $\begin{array}{l}\text { Apropriação do valor é condicionada à lógica da rede (com forte influência } \\
\text { da matriz), enquanto que a geração depende do desempenho no mercado } \\
\text { alvo }\end{array}$ \\
\hline
\end{tabular}

Fonte: elaboração própria

O último exemplo de Rede Global de Valorização proposto por este artigo é o das Redes com Mandatos por Competência (figura 6). Tais redes apresentam uma lógica muito semelhante às redes com mandatos geográficos. Isso porque além de apresentarem os mesmos determinantes da competitividade sistêmica, também organizam suas estruturas em torno de mandatos pré-estabelecidos para os diversos sites globais. Estes mandatos e a respectiva competitividade dos agentes dentro da rede dependem, no entanto, não de sua localização geográfica e sim de suas competências tecnológicas, organizacionais, produtivas, entre outras.

Como os fatores determinantes da competitividade e da alocação das funções são as capacitações dos agentes, observa-se o surgimento de estruturas bastante complexas. Estas são compostas desde startups e empresas de base tecnológica altamente especializadas em nichos até contract manufacturers globais, passando por filiais de empresas capitânias, laboratórios de $\mathrm{P} \& \mathrm{D}$ das capitânias e centros de pesquisas locais, além de fornecedores de produtos complementares.

Em geral, o que define as atividades a serem realizadas por estas empresas é a adequação de suas competências e rotinas a determinada trajetória tecnológica definida pelas empresas capitânias. Uma vez que estas são as responsáveis por definir e comandar o desenvolvimento tecnológico desta trajetória, 
também são as responsáveis pela apropriação da maior parcela do valor gerado na rede. Isso porque além de concentrarem em si as principais atividades, há grande dificuldade de mensurar a contribuição de um módulo específico - desenvolvido por uma das empresas constituintes da rede - para o valor do produto ou serviço final. Nesta mesma linha, Kraemer, Lindem \& Dedrick (2011, página 3), ao analisarem a apropriação de valor na rede de produção e inovação de produtos da Apple, concluem que:

"Assim como o iPod, o iPad e o iPhone geram grande receita para a Apple. Apesar do entusiasmo das empresas (fornecedoras de partes, peças e componentes) por integrarem a cadeia de suprimento destes produtos de grande sucesso, seus respectivos benefícios financeiros são pálidos em comparação com os da Apple" (tradução própria).

Assim, o valor distribuído às empresas constituintes muitas vezes é inferior ao seu potencial de contribuição para o valor final do produto ou serviço, e é estabelecido a partir de sua estrutura de custos interna.

Figura 6: Redes com Mandatos por Competências

\begin{tabular}{|c|c|}
\hline & Redes com Mandatos por Competências \\
\hline $\begin{array}{l}\text { Determinantes da } \\
\text { Competitividade Empresariais }\end{array}$ & Competências tecnológicas, organizacionais, produtivas, etc. \\
\hline $\begin{array}{l}\text { Determinantes da } \\
\text { Competitividade Sistêmicos }\end{array}$ & $\begin{array}{l}\text { Minimização da capacidade ociosa na rede global } \\
\text { Exequibilidade \& prazo } \\
\text { Custos globais da rede }\end{array}$ \\
\hline Estrutura da Rede & $\begin{array}{l}\text { Filiais de empresas capitânias } \\
\text { Laboratórios de P\&D das capitânias e centros de pesquisas locais } \\
\text { Fornecedores de produtos complementares } \\
\text { Variam deste pequenos elos altamente especializados em nichos até } \\
\text { contract manufacturers globais }\end{array}$ \\
\hline $\begin{array}{l}\text { Tipos de Atividades } \\
\quad \text { Realizadas }\end{array}$ & $\begin{array}{l}\text { Em geral associadas às rotinas e competências específicas de determinada } \\
\text { trajetória tecnológica }\end{array}$ \\
\hline Valoração & $\begin{array}{l}\text { Definida a partir da estrutura de custos e recursos da unidade executora. } \\
\text { Em geral há dificuldade de mensuração da contribuição de um módulo } \\
\text { específico para o valor do produto final }\end{array}$ \\
\hline
\end{tabular}

Fonte: elaboração própria

Além dos três tipos de redes globais de valorização propostos anteriormente, este artigo propõem uma categoria denominada de Redes de Suporte à Internacionalização (figura 7). Estas redes, apesar de estarem dispersas internacionalmente, não se configuram como uma unidade global de valorização do capital. Isso porque o principal objetivo das empresas capitânias não é segmentar suas atividades em módulos, distribuí-las globalmente de maneira a buscar menores custos e competências complementares, para posteriormente integrar novamente tais módulos e oferta-los a partir de uma única estratégia global.

No caso das Redes Suporte à Internacionalização, o que se observa é a constituição de redes bastante semelhantes e relativamente completas em todos os países que as empresas multinacionais atuam com o intuito de se fomentar e apoiar as atividades exclusivamente naquele local.

Assim, as estruturas de tais redes são comandadas por empresas multinacionais e constituídas por empresas locais de suporte como fornecedores, franquias, representantes, prestadores de serviços especializados, etc, para apoiar as atividades locais nos mais diversos países.

Estas, em geral realizam atividades como customização / localização, consultoria técnica, jurídica e de modelo de negócios locais, e a competitividade de cada uma destas empresas é determinada por sua capacidade de ofertar produtos e serviços complementares ao portfólio da empresa capitânia. Já no que diz respeito à competitividade sistêmica da rede, destacam-se fatores relacionados às vantagens de localização como conhecimento do modelo de negócio, da cultura empresarial, domínio de canais de comercialização e relações institucionais. 


\section{Figura 7: Redes de Suporte à Internacionalização}

\begin{tabular}{|c|c|c|}
\hline $\begin{array}{c}\text { Determinantes da } \\
\text { Competitividade Empresariais }\end{array}$ & $\begin{array}{c}\text { Redes de Suporte à Internacionalização de prestação de serviços complementares, existência de } \\
\text { produtos e serviços complementares }\end{array}$ \\
\hline $\begin{array}{c}\text { Determinantes da } \\
\text { Competitividade Sistêmicos }\end{array}$ & $\begin{array}{c}\text { Vantagens de localização: conhecimento do modelo de negócio, da cultura } \\
\text { empresarial, domínio de canais de comercialização, relações institucionais, } \\
\text { etc }\end{array}$ \\
\hline $\begin{array}{c}\text { Estrutura da Rede } \\
\text { Tipos de Atividades } \\
\text { Realizadas } \\
\text { Valoração }\end{array}$ & $\begin{array}{c}\text { Comandada por multinacional e constituídas por elos locais de suporte } \\
\text { como fornecedores, franquias, representantes, prestadores de serviços } \\
\text { especializados, etc }\end{array}$ \\
\hline $\begin{array}{c}\text { Realizam atividades de customização / localização, consultoria técnica, } \\
\text { jurídica , e de modelo de negócios locais, etc }\end{array}$ \\
\hline $\begin{array}{c}\text { Empresa capitânia distribui uma parte do valor do produto / serviço 'core' } \\
\text { às associadas. Adicionalmente, estas são remuneradas localmente pela } \\
\text { execução das demais atividades de suporte }\end{array}$
\end{tabular}

Fonte: elaboração própria

Uma vez que a maior parte dos agentes das Redes de Suporte à Internacionalização exercem atividades auxiliares, concentram-se em segmentos de menor valor agregado. Assim, a maior parte do valor gerado na rede concentra-se na empresa capitânia, a qual em alguns casos distribui uma parte do valor do produto / serviço 'core' às associadas (como em casos de atividades de consultorias vinculadas a metas de desempenho no mercado ou da execução de serviços de representação comercial). Adicionalmente, as empresas locais também, são remuneradas pela execução das demais atividades de suporte.

\section{Política industrial e tecnológica: breves considerações e alguns desdobramentos para o Brasil}

A partir da tipologia proposta pretende-se apresentar nesta seção um marco analítico que permita compreender os determinantes da efetividade da construção de uma política industrial e tecnológica (PI\&T) capaz de potencializar o desenvolvimento dos serviços intensivos em tecnologia associados à indústria 4.0.

Apresenta-se aqui um marco analítico generalista que contribui para o debate acerca da elaboração de estratégias nacionais de desenvolvimento destas atividades. Assim, não se pretende apresentar uma discussão detalhada das limitações e diretrizes para o caso brasileiro; pretende-se apenas, a partir deste marco analítico, sinalizar alguns apontamentos e limitações. Para tal, parte-se de três hipóteses:

i. admite-se que, tal qual se observa nas atividades manufatureiras globais, a hierarquização e a formação de redes de produção e inovação também tende a se reproduzir, com algumas variações, nas atividades de serviços intensivos em tecnologia que compõem o núcleo duro da indústria 4.0;

ii. dadas as diferentes configurações específicas destas redes, conforme descrito anteriormente, o grau de efetividade das políticas industriais e tecnológicas depende fundamentalmente de sua adequação às características específicas das redes que se procura fomentar;

iii. uma vez que tais redes apresentam caráter fluído e altamente segmentado, e dado o ritmo e intensidade de transformação a que estão susceptíveis os serviços intensivos em tecnologia, há a necessidade de se readequar os tradicionais instrumentos de política industrial e tecnológica. Estes, concebidos essencialmente a partir do padrão de acumulação fundamentado em uma lógica produtivista-fordista (principalmente no Brasil), em muitos casos mostram-se institucionalmente inadequados à lógica de desenvolvimento $\mathrm{e}$ acumulação características destas atividades.

A partir destas hipóteses, o marco analítico proposto neste trabalho sugere que a formulação de políticas deve levar em consideração os condicionantes para sua efetividade a partir de quatro dimensões: tecnológica, institucional, nível de desenvolvimento da estrutura empresarial e grau de competitividade sistêmica local. 
Na dimensão tecnológica a principal questão a ser observada é o grau de horizontalidade e padronização das tecnologias em questão. Isso porque na medida em que aumenta o grau de generalidade na aplicação destas, maior tende a ser a importância da concentração em torno de poucas plataformas tecnológicas e maiores são as externalidades de rede e os efeitos de lock-in (GAWER e HENDERSON, 2005; CUSUMANO \& GAWER, 2001)

Assim, a tendência é de que prevaleçam forças centrípetas que levam à concentração das estruturas de mercado em um número muito reduzido de agentes em escala global (ROSELINO, 2006). Tal concentração tende a ocorrer em tecnologias compreendidas como bastante transversais, pouco setoresespecíficas e essencialmente habilitadoras da indústria 4.0 como aquelas relacionadas à cloud computing e big data, as quais tem como principais players globais empresas como Amazon e Google. Ou seja, admitese que nesse cenário de alta generalidade, concentração muito grande em torno de plataformas dominantes e elevada vigência de externalidades de rede, as possibilidades de efetivação das políticas industrial e tecnológica são bastante restritas.

Ao contrário, em segmentos tecnológicos onde se verifique baixo grau de generalidade, baixas externalidades de rede e efeitos de lock-in, assim como a existência da compreensão de especificidades setoriais como um importante determinante da competitividade, tende-se a observar o prevalecimento da força centrífuga e estruturas de mercado menos concentradas. Neste cenário, o condicionante tecnológico tende a contribuir positivamente para a efetividade das políticas.

$\mathrm{Na}$ dimensão institucional, os condicionantes para a elaboração de políticas devem levar em consideração fundamentalmente a capacidade de desenho e implementação das mesmas. Assim, deve-se avaliar a capacidade da infraestrutura institucional para conceber instrumentos de políticas adequados ao perfil das atividades de serviços intensivas em conhecimento, ressaltando-se que os mesmos se estruturam em lógica de acumulação bastante distinta daquela característica do padrão produtivista-fordista a partir do qual se desenharam os instrumentos de política industrial tradicionais. (SUZIGAN e FURTADO, 2006). Adicionalmente, a estratégia de formulação de política deve levar em consideração sua real capacidade de influenciar as decisões dos agentes econômicos, a fim de se viabilizar sua efetividade. Para tal, características como a relevância do mercado nacional em questão são centrais.

Nesta mesma linha de argumentação, os condicionantes empresariais devem ser analisados como importantes elementos para a efetividade das políticas industriais e tecnológicas (SARTI e HIRATUKA, 2017). De maneira geral, a primeira constatação a ser analisada deve ser o nível e a capacidade de aprendizado dos agentes (COHEN e LEVINTHAL, 1989). Em paralelo, segue-se a necessidade de se compreender a relação entre estrutura do mercado e a potencial efetividade destas políticas. Assim, admitese que esta é menor em segmentos muito concentrados, dominados por empresas multinacionais, para os quais o mercado nacional é pouco relevante. $\mathrm{O}$ inverso se verifica nos casos em que há forte presença de empresas nacionais, com elevada capacidade de aprendizado e para as quais o mercado nacional é bastante relevante.

Por fim, os condicionantes sistêmicos também são centrais para se compreender o arcabouço analítico para formulação de políticas industriais e tecnológicas proposto nesta sessão (COUTINHO \& KUPFER, 2015). Para tal, de maneira geral deve-se compreender em perspectiva comparada ao cenário internacional o grau de competitividade da estrutura produtiva de determinado país. Em paralelo é necessário avaliar, também em perspectiva comparada, o grau de desenvolvimento do sistema nacional de inovação. Neste cenário, caso ambos se apresentem em níveis de desenvolvimento elevado, o espaço para a formulação de uma estratégia que busque fomentar o desenvolvimento de soluções tecnológicas locais é maior. Do contrário, as estratégias devem-se direcionar para segmentos nas redes onde tais exigências sejam menos patentes.

Levando-se em consideração a combinação dos condicionantes tecnológicos, institucionais, empresariais e acerca do grau de competitividade sistêmica local, propõem-se que a diretrizes de PI\&T tenham objetivos e estratégias distintas a partir de seu potencial de efetividade e do nível de competências tecnológicas / capacidade de aprendizado em curto prazo dos agentes locais frente aos concorrentes internacionais. 
Assim, em segmentos em que haja, dados os condicionantes explicitados anteriormente, um elevado grau de efetividade das PI\&T e elevado nível de competências tecnológicas locais, sugere-se que estas políticas concentrem em esforços na busca de desenvolver soluções tecnológicas locais (vide quadro 1).

Já em segmentos com elevado grau de efetividade, mas com baixo nível de competências tecnológicas, a estratégia mais virtuosa de PI\&T parece ser aquela voltada à concentração dos agentes em atividades de médio valor agregado, acoplando-se às demandas da estrutura produtiva doméstica e beneficiando-se do conhecimento dos modelos de negócio locais.

Nos segmentos em que se verifica uma baixa efetividade das PI\&T (seja em virtude da vigência de uma estrutura de mercado altamente concentrada, ou da incapacidade de se influenciar as trajetórias tecnológicas das plataformas dominantes) mas com nível elevado de competências tecnológicas locais, as diretrizes mais bem sucedidas ao desenvolvimento dos serviços intensivos em conhecimento parecem estar vinculadas a iniciativas de fomento da competitividade sistêmica, para além de políticas concentradas em segmentos específicos pouco influenciáveis. Dentre as medidas desta estratégia destacam-se o fomento ao sistema nacional de inovação e a disponibilidade de recursos em prazos e volumes adequados ao financiamento do crescimento das empresas de base tecnológica.

Já nos segmentos em que a baixa efetividade das PI\&T se combina com o baixo nível de desenvolvimento das competências tecnológicas, a estratégia mais adequada parece ser a de incorporação de tecnologias e de fomento à sua difusão a fim de se viabilizar a atualização tecnológica e o aumento da produtividade da estrutura produtiva local.

\section{Quadro 1: Estratégias de política industrial e tecnológica (PI\&T) para o desenvolvimento se serviços intensivos em tecnologia relacionados à indústria 4.0.}

\begin{tabular}{|c|c|c|c|}
\cline { 3 - 4 } \multicolumn{2}{c|}{} & \multicolumn{2}{c|}{ Grau de efetividade das PI\&T } \\
\cline { 2 - 4 } \multicolumn{2}{c|}{$\begin{array}{c}\text { Nível de } \\
\text { competências } \\
\text { tecnológicas } \\
\text { dos agentes } \\
\text { locais }\end{array}$} & Elevado & $\begin{array}{c}\text { Elevado } \\
\text { Baixo }\end{array}$ \\
\cline { 3 - 4 } & Baixo & $\begin{array}{c}\text { Fomento à competitividade } \\
\text { sistêmica e financiamento às } \\
\text { empresas de base tecnológica }\end{array}$ & $\begin{array}{c}\text { Incorporação de tecnologias e } \\
\text { de fomento a sua difusão com } \\
\text { lomistas a aumentar a } \\
\text { produtividade da estrutura } \\
\text { produtiva }\end{array}$ \\
\hline
\end{tabular}

Fonte: elaboração própria

É exatamente a partir da combinação da análise destes condicionantes e das hipóteses apresentadas anteriormente que este artigo sugere que devam ser formuladas as estratégias brasileiras de política industrial e tecnológica para se fomentar os serviços intensivos em tecnologia associados à indústria 4.0.

Neste cenário, para o caso brasileiro, admite-se que a estratégia de inserção no que a tipologia apresentada neste artigo denomina de redes com enforcement institucional, redes de suporte à internacionalização e redes com mandatos geográficos parece ser a opção inicial nas quais a efetividade das PI\&T locais tende a ser mais elevada.

Com relação às redes com enforcement institucional, vale destacar que a lógica sobre a qual se sustenta historicamente grande parte da PI\&T brasileiras basicamente é estruturada a partir desta perspectiva. Com o intuito de potencializar sua efetividade e adequá-las às características dos serviços intensivos em tecnologia, sugere-se a reorganização do sistema de condicionalidades (sejam eles de financiamento, de compras públicas e de incentivo tecnológico como Lei de Informática). A ideia geral é a de que tais instrumentos transfiram suas métricas de avaliação de indicadores relacionados a etapas do Processo Produtivo Básico para outros relacionados ao perfil e à intensidade tecnológica das atividades realizadas. Assim, a título de ilustração setorial, as contrapartidas exigidas para se usufruir dos benefícios fiscais da Lei de Informática não estariam condicionadas à realização de etapas fundamentalmente de montagem dos componentes importados. Ainda nesta ilustração, tais benefícios seriam proporcionais à intensidade tecnológica das atividades realizadas, as quais poderiam ser avaliadas a partir de diversas métricas, como o percentual de empregos locais vinculados a atividades de alta e média complexidade 
tecnológica, entre outras. Vale destacar que estas métricas são muito mais efetivas - e menos susceptíveis a práticas de rent seeking - para se avaliar as atividades realizadas domesticamente. Este sistema de condicionalidades ainda poderia estabelecer prêmios (tributários ou menores taxas de juros, a depender do instrumento de incentivo utilizado em cada caso) a empresas que apresentassem determinada participação das exportações na receita total.

Com relação às redes de suporte à internacionalização e as redes com mandatos geográficos, dada a relevância do mercado doméstico e o grau relativamente elevado de diversificação da estrutura produtiva local, parece se vislumbrar espaço para o fomento a atividades de médio valor agregado, nas quais a interação local e o conhecimento das especificidades do mercado brasileiro e do modelo de negócios seja uma variável relevante para a competitividade.

Já para as redes denominadas neste trabalho de coevolutivas e atomizadas e àquelas com mandatos por competências, a estratégia com maior efetividade parece ser a concentração de recursos em áreas em que não sejam caracterizadas por tecnologias essencialmente generalistas onde predominem plataformas tecnológicas globalmente concentradas em poucas empresas. Assim, em áreas onde coexistam elevada efetividade e elevada competência tecnológica, o financiamento dos esforços tecnológicos das empresas estabelecidas é central para seu incremento de competitividade, assim como a utilização de instrumentos de compras públicas em segmentos vinculados a oferta de infraestrutura social (como esforços para a implementação de inteligência artificial em grandes centros urbanos, na gestão do complexo da saúde e de e-gov, entre outros) (ROCHA, 2019).

Nas áreas em que tanto a efetividade quanto o nível de competências tecnológicas não sejam elevados, a diretriz sugerida é a concentração em políticas transversais de fomento ao surgimento de startups em nichos associados a mudanças futuras no atual paradigma e a demandas históricas da sociedade brasileira (BIELSCHOWSKY, 2014; GADELHA, 2003; HIRATUKA et al, 2008; FAGNANI et al, 2018). Em paralelo, em segmentos com alta concentração global e elevada pervasividade na estrutura produtiva, as PI\&T devem levar em consideração a necessidade de se fomentar incorporação de tecnologias e de fomento à sua difusão a fim de se viabilizar a atualização tecnológica e o aumento da produtividade da estrutura produtiva local.

Por fim, uma vez que a principal fonte de assimetria nas redes competitivas globais reside na concorrência internacional em busca de menores custos produtivos, que muitas vezes se fundamentam em elementos como taxa de câmbio desvalorizada, elevados subsídios físcais e creditícios, e baixos custos relativos da mão de obra, admite-se que o direcionamento das PI\&T para a integração nestas redes a partir de uma lógica export-led growth é pouco compatível com uma estratégia de desenvolvimento virtuosa, dada a estrutura socioeconômica brasileira.

\section{Considerações Finais}

Este artigo analisou a relação entre o desenvolvimento dos serviços intensivos em tecnologia e o debate acerca do surgimento da indústria 4.0. A partir da concepção de que tais atividades representam importância estratégica para o novo paradigma tecno-produtivo em gestação, buscou-se compreender os condicionantes das estratégias de desenvolvimento destes serviços nos marcos das redes globais de produção e inovação. Ou seja, admite-se neste trabalho que, assim como se observa nas atividades manufatureiras globais, a hierarquização e a formação de redes também tendem a se reproduzir, com algumas variações, nas atividades de serviços intensivos em tecnologia associadas à indústria 4.0.

Dadas as diferenças qualitativas na forma de construção, hierarquização e apropriação do valor entre as diversas configurações possíveis destas redes, este artigo busca contribuir com a literatura ao estabelecer uma tipologia das mesmas. Assim, segmenta-as em redes com enforcement institucional, redes coevolutivas e atomizadas, redes competitivas, redes com mandatos geográficos, redes com mandatos por competências e redes de suporte à internacionalização. Para cada uma destas configurações mostrou-se que os determinantes da competitividade, a estrutura da rede, o tipo de atividades realizadas e a estratégia de apropriação do valor condicionam as possibilidades de desenvolvimento dos agentes inseridos nessas configurações. 
Uma contribuição adicional pretendida pelo trabalho é, a partir desta tipologia, a proposição de um marco analítico para o estabelecimento de diretrizes normativas de política industrial e tecnológica que potencializem o desenvolvimento de tais atividades. Este marco leva em consideração condicionantes de natureza tecnológica, institucional, estrutura empresarial e o grau de competitividade sistêmica local para apontar diretrizes adequadas a cada uma das formas de redes da tipologia proposta.

A partir destas contribuições e de uma breve análise dos condicionantes da PI\&T brasileira relacionada aos serviços intensivos em tecnologia, apresentaram-se alguns apontamentos à possíveis estratégias de desenvolvimento de tais serviços em distintas possibilidades de configurações destas redes.

Estas estratégias situam-se basicamente em quatro eixos, que levam em consideração o grau de efetividade das políticas e o nível de desenvolvimento das competências tecnológicas locais. Materializamse, deste modo, em: i. desenvolvimento tecnológico local (quando há elevada efetividade e elevado nível de desenvolvimento); ii. fomento a atividades de médio valor agregado, vinculadas à estrutura produtiva doméstica (reduzida efetividade e elevado desenvolvimento); iii. fomento à competitividade sistêmica e financiamento às empresas de base tecnológica (elevada efetividade e reduzido desenvolvimento) e, iv. incorporação de tecnologias e de fomento à sua difusão com vistas a aumentar a produtividade da estrutura produtiva (reduzida efetividade e reduzido desenvolvimento).

Por fim, a partir de uma leitura de economia política da política industrial, cabe destacar que além dos evidentes benefícios do desenvolvimento destas atividades para o incremento da produtividade do parque produtivo local, o incentivo a estas enfrentaria menores resistências por parte dos interesses organizados em torno do establishment político e econômico, em suas dimensões produtiva, comercial e financeira. Isso porque, ao contrário da lógica tradicional de PI\&T baseada na substituição de importações, o incentivo a estas atividades tenderia inclusive no curto prazo a reduzir os custos produtivos dos setores demandantes destes serviços ao mesmo tempo em que contribuiria para o aumento de sua produtividade. Por último, porém não menos importante, a necessidade de recursos para o forte incentivo aos serviços industriais intensivos em conhecimento seria menor quando comparada aos esforços tradicionais de PI\&T para o desenvolvimento de setores manufatureiros característicos do padrão produtivo da II Revolução Industrial, dada sua menor intensidade de capital por trabalhador.

De maneira adicional, os incentivos tributários aos inúmeros segmentos destes serviços vinculados à indústria 4.0 não exigiria elevadas renúncias fiscais, uma vez que a base de tributação da maioria destas é reduzida, dado seu estágio inicial de desenvolvimento.

\section{Referências bibliográficas}

ANDERSON, C. (2006). A Cauda Longa - Do Mercado de Massa para o Mercado de Nicho, Editora Campus.

ARTHUR, W. B. "Positive feedbacks in the economy". Scientific American, 262: 92-99, 1990.

ATHREYE, S., The Indian Software Industry, in Arora, Ashish., \& Gambardella, Alfonso (org), From Underdogs to Tigers: The Rise and Growth of the Software Industry in Brazil, China, India Ireland, and Israel, Oxford University Press, 2005.

BIELSCHOWSKY, R. (2014). "Estratégia de desenvolvimento e as três frentes de expansão no Brasil: um desenho conceitual”, In: Calixtre, A.; Biancarelli, A.; Cintra, M. A.. (Org.). Presente e Futuro do Desenvolvimento Brasileiro. 1ed. Brasília: Ipea (pp. 195-225).

BRESNAHAN, T. \& GREESTEIN, S. "Technological Competition and the Structure of the Computer Industry”. The Jounal of Indústrial Economics, Volume XLVII, March, 1999.

BROEDNER, P. Industrie 4.0 und Big Data-wirklich ein neuer Technologieschub?. In: Digitalisierung industrieller Arbeit. Nomos Verlagsgesellschaft mbH \& Co. KG, 2015. p. 232-251.COHEN, W. M.; LEVINTHAL, D. A. Innovation and Learning: The Two Faces of R\&D. The Economic Journal, v. 99, $\mathrm{n}$. 397, p. 569-596, set. 1989.

COUTINHO, L.; A Terceira revolução industrial e tecnológica, Revista Economia e Sociedade número 1, Instituto de Economia - Unicamp, 1992.

COUTINHO, L.; KUPFER, D. (2015). As Múltiplas Oportunidades de desenvolvimento e o Futuro da Indústria Brasileira, in ADBI, Dez anos de política industrial balanço \& perspectivas - 2004-2014. 
CHANDLER, A. Scale and Scope. Cambridge, Mass.: Harvard University Press. (1990).

CHESNAIS, F. A Mundialização do Capital, Xamã Editora, São Paulo, 1996.

COLOMBO,D. (2009) A política pública de incentivo ao setor de informática no Brasil a partir da década de 90: uma análise jurídica. Dissertação de Mestrado, USP - Faculdade de Direito.

CROTTY, J. "The effects of increased product market competition and changes in financial markets on the performance of Nonfinancial Corporations in the neoliberal era". PERI Working paper, n. 44, 2002.

CUSUMANO, M. A. \& GAWER, A. Driving High-Tech Innovation: The Four Levers of Platform Leadership. Paper 152, Center for e-Business@MIT, October, 2001.

DEDRICK, J.; KRAEMER, K.L. \& Dunkle, D. Offshore New Product Development: Survey Results, University of California, Irvine, February 2009.

DEDRICK, J.; KRAEMER, K.L. \& Linden, G. Capturing Value in a Global Innovation Network: A Comparison of Radical and Incremental Innovation, Personal Computing Industry Center, UC Irvine, Draft Version, 2007.

ERNST, D. "The Economics of Electronics Industry: Competitive Dynamics and Industrial Organization", East-West Center Working Papers, Economics Series No. 7, October, 2000.

ERNST, D. \& KIM, L. "Global production networks, knowledge diffusion, and local capability formation". Research Policy, n. 31, p. 1417-1429, 2002.

FAGNANI, E.; DWECK, E.; MELLO, G.; ROCHA, M.A. \& ROSSI, P. (2018). Desenvolvimento social e estrutura produtiva. Cadernos De Debates - 3 - Projeto Brasil Popular.

GADELHA, C. (2003) O complexo industrial da saúde e a necessidade de um enfoque dinâmico na economia da saúde. Ciênc Saúde Coletiva. 2003;2:521-35.

GAWER, A. \& CUSUMANO, M. A.. Platform leadership: how Intel, Microsoft and Cisco drive industry innovation. Harvard Business School Press, 2002.

\& HENDERSON, R. "Platform Owner Entry and Innovation in Complementary Markets: Evidence from Intel", NBER Working Paper 11852, Cambridge, December, 2005.

HIRATUKA, et. al. (2008) Importância Socioeconômica da Cadeia de Serviços de Saneamento Básico no Brasil, Encontro da Anpec.

HIRSCH-KREINSEN, H. "Industry 4.0 as promising technology: emergence, semantics and ambivalent character. digitization of manufacturing and industrialwork. Soziologisches Arbeitspapier Nr. 48, 2016.

JASPERNEITE, J. ALTER WEIN IN NEUEN SCHLÄUCHEN. INTERNET: http://www. ciitowl. de/uploads/media/410-10\% 20gh\% 20jasperneite\% 20ca, 2012.

LAZONICK, W \& SULLILIVAN, M.O. "Maximizining shareholder value: a new ideology for corporate governance". Economy and Society, vol.29 n.1, pp. 13-35, 2000.

PROCHNIK, V., LABRUNIE, M. L., SILVEIRA, M. A., \& RIBEIRO, E. P. (2015). A política da política industrial: o caso da Lei de Informática. Revista Brasileira De Inovação, 14, 133-152. https://doi.org/10.20396/rbi.v14i0.8649103

ROSENBERG, N. “On Technological Expectations”. Economic Journal. Volume 86, Issue 343. Sept., p..523-535, 1976.

ROSELINO, J.E.S. (2006). A INDÚSTRIA DE SOFTWARE: O 'modelo brasileiro' em perspectiva comparada. Tese de Doutoramento. Instituto de Economia, Universidade Estadual de Campinas: Campinas. ROSELINO, J. E.; GARCIA, R. (2002) . The Informatics Law and its Effcts on the Brazilian Electronic Complex Industry? A Critical Evaluation. In: 6th Annual EUNIP (European Network on Industril Policy) Conference.

SALLES FILHO, S.; STEFANUTO, G.; MATTOS, C.; ZEITOUM, C.; CAMPOS, F. R. Avaliação de impactos da Lei de Informática: uma análise da política industrial e de incentivo à inovação no setor de TICs brasileiro. Revista Brasileira de Inovação, v. 11, n. esp., p. 191-218, 2012.

SANTOS, Felipe Lucena Andrade, China e a Indústria 4.0, uma análise comparativa. Dissertação de mestrado, Programa de Pós-Graduação Em Economia, Universidade Federal de São Carlos - UFSCar, 2019.

SARTI, Fernando; HIRATUKA, Célio. (2017) Desempenho recente da indústria brasileira no contexto de mudanças estruturais domésticas e globais. Campinas: Unicamp. IE. TD290. 
STURGEON, T. J. T, "Modular production networks: a new American model of industrial organization". Industrial and Corporate Change, Volume 11, Number 3, pp. 451-496, 2002.

SUZIGAN, W.; FURTADO, J. (2006). Política Industrial e Desenvolvimento. Revista de Economia Política, vol. 26, nº 2 (102), pp. 163-185 abril-junho.

ZYSMAN, J., MURRAY, J., FELDMAN, S., NIELSEN, N. C., \& KUSHIDA, K. E. Services with everything: The ICT-enabled digital transformation of services, BRIE Working Paper 187a, 2010. 